\title{
Dual Band Microstrip Patch Array Antenna for LTE Applications in Malaysia
}

\author{
A. Salisu ${ }^{1,2}$, A. S. Hussaini ${ }^{2,3,4}$, I.T.E. Elfergani ${ }^{4}$, B. A. Mohammed ${ }^{2}$, Wisdom Anuhu ${ }^{3}$, \\ R.A. Abd-Alhameed ${ }^{2}$, J. Rodriguez ${ }^{4,5}$ \\ ${ }^{1}$ Department of Electrical Engineering, Modibbo Adama University of Technology, Yola \\ abubakarsalisu06@mautech.edu.ng \\ ${ }^{2}$ University of Bradford, Bradford, BD7 1DP, UK, \\ \{r.a.a.abd, a.s.hussaini7\}@bradford.ac.uk \\ ${ }^{3}$ School of Engineering, American University of Nigeria, Yola \\ \{wisdom.anuhu, ash.hussaini\} @aun.edu.ng \\ ${ }^{4}$ Instituto de Telecomunicações - Aveiro, Portugal \\ \{i.t.e.elfergani, ash, jonathan $\} @$ av.it.pt \\ ${ }^{5}$ University of South Wales, Pontypridd CF37 1DL, UK \\ jonathan.rodriguez@southwales.ac.uk
}

\begin{abstract}
LTE is the latest step in the telecommunication development. The expansion of LTE is largely due to the success of the high-speed packet access and the overgrowing need for capacity. A dual band microstrip patch array antenna for LTE applications in Malaysia has been proposed. Firstly, a single element antenna is designed to resonate at $1.8 \mathrm{GHz}$ and $2.6 \mathrm{GHz}$, and the dimensions were calculated using transmission line model. Then, to achieve higher directivity, antenna arrays with two and four number of elements have been applied. A microstrip feed line with $3 \mathrm{~dB}$ divider is used to feed each of the elements. Simulations are been carried out using CST Microwave Studio. Subsequently, simulation results are compared and analyzed. From the results, the $4 \times 1$ array antenna configuration has shown the best results with directivity of $11.2 \mathrm{~dB}$ and $12.9 \mathrm{~dB}$ at $1.8 \mathrm{GHz}$ and $2.6 \mathrm{GHz}$ respectively.
\end{abstract}

Keywords: LTE: Long Term Evolution, CST: Computer Simulation Technology..

\section{Introduction}

Two different planar antennas operate with similar features, in terms of impedance matching and radiation, at two different frequencies. To obtain these, by using planar technologies is not straight forward, more especially when intrinsic structural and technological simplicity typical of patch antennas is to be considered [16]. In addition, dual frequency antennas may provide an alternative solution for high speed data application such as 
LTE application. In the following, one of the ways to improve overall gain of the dual band antenna is to use antenna array configuration. By increasing the array elements, the antenna directivity can be improved.

Microstrip patch antenna has broad practical application in wireless communication because it offers ease, lesser cost of fabrication and integration with feeding network. In microstrip antenna, rectangular, square and triangle shapes exist. For microstrip configuration, the conducting material (patch) is attached on one end of the dielectric substrate with ground plane on the backside. It can be feed by either series or corporate feeding arrangement [2].

However, the main drawback of microstrip patch antenna is that, it has very narrow bandwidth. This effects can be reduced by employing different feeding method, array configuration, ground plane, and dielectric materials [3] .

Array antenna element is a collection of similar radiating element. The word 'similar radiators' means the element possess the same element, regular spacing, with the similar feeding arrangement oriented in the same direction in three dimensional space. Antenna array is generally used to direct the radiated power to the targeted angular sector [ $\underline{3}]$. Moreover, array antenna has the ability to scan antenna beam, improve its directivity and numerous important functions which could not be attained by single element. Array antenna performance can be raised by increasing the array elements. However, size, cost and complexity rise as the number of the element increased [4]].

Table 1 LTE bands with their frequency allocation []

\begin{tabular}{|c|c|}
\hline LTE Band Number & Allocation $(\mathrm{MHz})$ \\
\hline 8 & $880-915$ \\
\hline 11 & $1427.9-1452.9$ \\
\hline 22 & $3410-3500$ \\
\hline 34 & $2010-2025$ \\
\hline 36 & $1930-1990$ \\
\hline 38 & $2570-2620$ \\
\hline 39 & $1880-1920$ \\
\hline
\end{tabular}

This paper initially presents an optimised rectangular microstrip patch antenna operating at a single frequency of $1.8 \mathrm{GHz}$, and then obtained the second frequency $2.6 \mathrm{GHz}$ by introducing a slot or cut in U-shaped to one radiating edge, thereby producing an antenna operating at two different frequencies $(1.8 \mathrm{GHz}$ and $2.6 \mathrm{GH})$ respectively. This antenna is then optimised into $2 \times 1$ and $4 \times 1$ array antenna to improve the gain.

\section{Design, Simulation and Fabrication}

The design, simulation and fabrication results for the single element, $2 \times 1$ and $4 \times 1$ microstrip array antennas is discussed. The proposed design antenna element is analysed using computer simulation technology (CST) microwave studio 2014 software. Effect of the reflection coefficient, bandwidth, directivity and other simulation parameters was clearly been observed. Additionally, comparison between the measured and simulated results were presented. 
This section is to design single element dual band microstrip patch antenna. The single element consists of radiating patch, inset feed line, substrate and ground plane. Width (W), length (L), of the patch was calculated[19]. SMA connector is used to connect the inset feed line. The use of slot or cut allows a frequency ratio of 1.3 to 3 [15]. Figure 1 shows a single element dual band microstrip patch antenna resonating at $1.8 \mathrm{GHz}$ and $2.6 \mathrm{GHz}$ respectively.

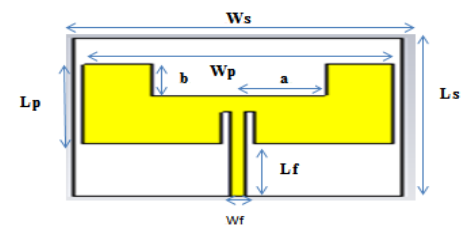

Figure 1. Single element dual band microstrip patch antenna

From Figure 1, it can be seen that U-shaped cut denoted by a and $\mathrm{b}$ dimensions gives the second frequency at $2.6 \mathrm{GHz}$. The dimensions of the slot or cut a and b was first optimised to get a better result.

\subsection{Proposed Array Antenna Structure}

Dual band microstrip patch array antenna is designed in this work, starting with single element, $2 \times 1$ elements and finally to the $4 \times 1$ elements at $1.8 \mathrm{GHz}$ and $2.6 \mathrm{GHz}$ for LTE applications in Malaysia. Corporate feed with T-junction power divider is used to fed the microstrip patch array antenna. Figure 1.1, 1.2 and 1.3 show the optimized geometries of the single element, $2 \times 1$ elements, and $4 \times 1$ elements of the dual band microstrip patch array antennas respectively. Initially, single element was designed and simulated. Simulation results were then evaluated in terms of frequency of operation, radiation pattern, gain and impedance bandwidth. Then the single element was transformed to $2 \times 1$ dual band antenna array and finally to 4 x 1 linear arrays. After optimization, it has been observed that, the best result regarding to the element inter-spacing is found to be $72.77 \mathrm{~mm}$. The complete dimensions of the proposed single and $2 \times 1$ elements dual band microstrip antenna are shown in Figure 2 and is tabulated in Table 2 and 3 .

Table 2 : Design specifications and parameters of single element dual band antenna

\begin{tabular}{|l|l|c|}
\hline Description & Parameter & Value (mm) \\
\hline Patch width & Wp & 59.28 \\
\hline Patch length & Lp & 37.5 \\
\hline Substrate width & Ws & 63 \\
\hline Substrate length & Ls & 75 \\
\hline Feeding length & Lf & 25 \\
\hline Feeding width & Wf & 3.14 \\
\hline
\end{tabular}




\begin{tabular}{|l|l|l|}
\hline Gap width & $\mathrm{Wg}$ & 1.7 \\
\hline Gap Length & $\mathrm{Lg}$ & 15 \\
\hline Slot cut width & $\mathrm{a}$ & 16.66 \\
\hline Slot cut horizontal & $\mathrm{b}$ & 14.22 \\
\hline
\end{tabular}

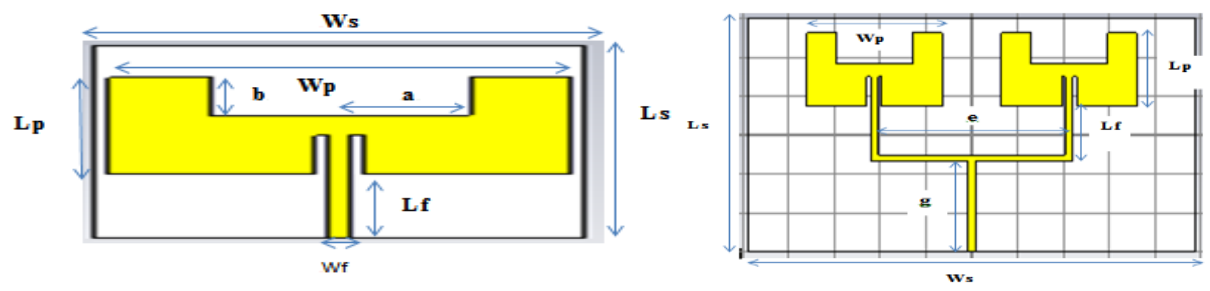

Figure 2 Geometry of single and 2 x 1 elements dual band microstrip array antenna

The single is then transformed into $2 \times 1$ dual band array antenna using a corporate $\mathrm{T}$ junction feeding technique as shown in Figure 3. The dimensions is tabulated in Table 3.

Table 3 Design specification and parameters of $2 \times 1$ dual band microstrip array antenna

\begin{tabular}{|l|l|l|}
\hline Description & Parameter & $\begin{array}{c}\text { Value } \\
(\mathrm{mm})\end{array}$ \\
\hline Patch width & Wp & 59 \\
\hline Patch length & Lp & 37.5 \\
\hline Substrate width & Ws & 195 \\
\hline Substrate length & Ls & 120 \\
\hline Feeding length & Lf & 25 \\
\hline Feeding width & Wf & 3.137 \\
\hline Gap length & Lg & 15 \\
\hline Slot width & $\mathrm{a}$ & 16.66 \\
\hline Slot cut length & $\mathrm{b}$ & 15.62 \\
\hline Element spacing & $\mathrm{e}$ & 85 \\
\hline Vertical feed length & $\mathrm{g}$ & 48 \\
\hline Horizontal feed length & $\mathrm{f}$ & 3.137 \\
\hline
\end{tabular}

The $2 \times 1$ dual band microstrip array antenna is then transformed into $4 \times 1$ dual band microstrip antenna. The new $4 \times 1$ array antenna configuration is shown in Figure 4 and it tabulated dimensions are presented in Table 4. 
Table 4 Design specifications and parameters of 4 x 1 array antenna

\begin{tabular}{|l|c|c|}
\hline Description & Parameter & $\begin{array}{c}\text { Value } \\
(\mathrm{mm})\end{array}$ \\
\hline Patch width & $\mathrm{Wp}$ & 59 \\
\hline Patch length & Lp & 37.5 \\
\hline Substrate width & Ws & 221 \\
\hline Substrate length & Ls & 128 \\
\hline Feeding length & Lf & 22.8 \\
\hline Feeding width & Wf & 3.137 \\
\hline Gap length & Lg & 15 \\
\hline Slot width & $\mathrm{a}$ & 16.66 \\
\hline Slot cut length & $\mathrm{b}$ & 15.62 \\
\hline Element spacing & $\mathrm{e}$ & 83 \\
\hline Vertical feed length & $\mathrm{g}$ & 44.3 \\
\hline Horizontal feed length & $\mathrm{f}$ & 3.137 \\
\hline
\end{tabular}

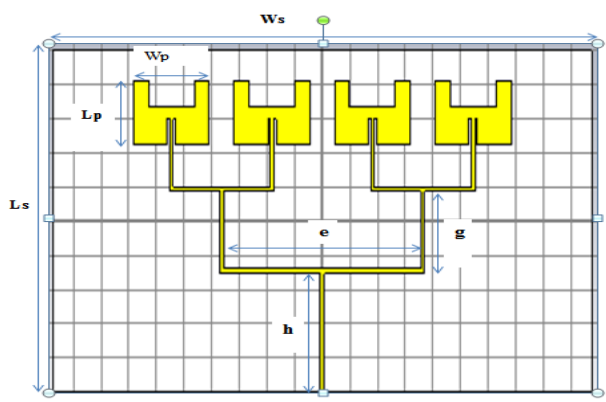

Figure 4 4x1 element dual band microstrip array antenna

\subsection{Simulation Results}

The simulation results of a dual band microstrip array antenna operate at $1.8 \mathrm{GHz}$ and $2.6 \mathrm{GHz}$ respectively are presented. In the following, the antenna performances are showed and discussed.

\subsubsection{Reflection Coefficient and Impedance Bandwidth}

Figure 5 shows reflection coefficient response (|S11 dB |) for simulation results of the dual band microstrip patch array antenna for single-element, 2 x 1 elements and $4 \times 1$ element array respectively. It can be seen that the antennas resonate at $1.8 \mathrm{GHz}$ and $2.6 \mathrm{GHz}$, for single element with $|\mathrm{S} 11|$ below $-16.53 \mathrm{~dB}$ and $-27.18 \mathrm{~dB}$. Meanwhile, for $2 \times 1$ elements, the refelection coeefficient response below $-16.14 \mathrm{~dB}$ and $-31.11 \mathrm{~dB}$ have been obtained at $1.8 \mathrm{GHz}$ and $2.6 \mathrm{GHz}$ respectively. For $4 \times 1$ elements array antenna, it can be noticed that the antenna resonates at $1.8 \mathrm{GHz}$ and $2.64 \mathrm{GHz}$ with the reflection coefficient $|\mathrm{S} 11|$ below $-23.47 \mathrm{~dB}$ and - 
$24.37 \mathrm{~dB}$. As for the $-10 \mathrm{~dB}$ impedance bandwidth,the simulation results show antenna bandwidth of $55 \mathrm{MHz}$ and $99 \mathrm{MHz}$ for single element, $32 \mathrm{MHz}$ and $59 \mathrm{MHz}$ for $2 \times 1$ elements and $38 \mathrm{MHz}$ and $51 \mathrm{MHz}$ for $4 \times 1$ elements at resonances.

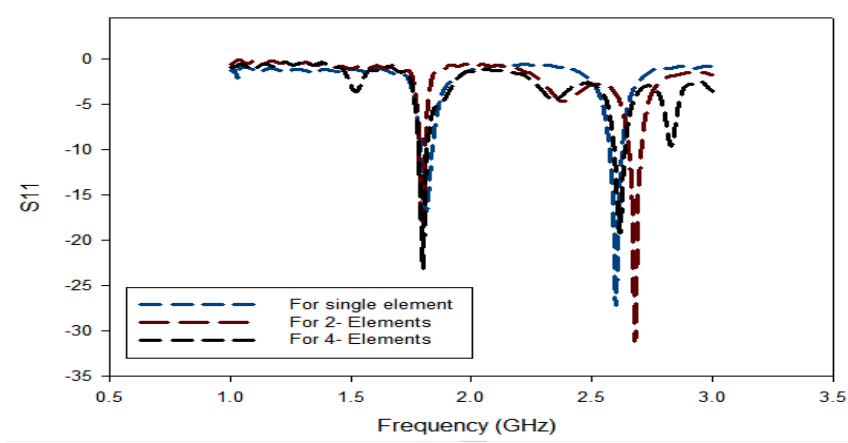

Figure 5 Results of a single element, 2 x 1 and 4 x 1 array element reflection coefficient

It can be observed that only the single element antenna operate at the exact operating frequencies of $1.8 \mathrm{GHz}$ and $2.6 \mathrm{GHz}$, while a litlle shift in the operating frequencies is observed for $2 \times 1$ and $4 \times 1$ array antenna respectively. This might be due to the fringing effect in the fields of the antenna. Moreover, reflection coefficient magnitude for all the antennas is found below $-10 \mathrm{~dB}$ at resonance frequencies.

\subsubsection{Radiation Pattern}

The radiation characteristics of the simulated dual band microstrip patch array antenna at both frequency of operation are shown in Figure 6. Figure 6 represents the simulated polar plot radiation pattern result at $1.8 \mathrm{GHz}$ and $2.6 \mathrm{GHz}$. It can be clearly observed that single element and $2 \times 1$ elements array antennas have a main lobe that is broadside with small back lobe. Meanwhile, for the $4 \times 1$ elements antenna array, the radiation pattern is more directional with a narrower beamwidth in the main beam.
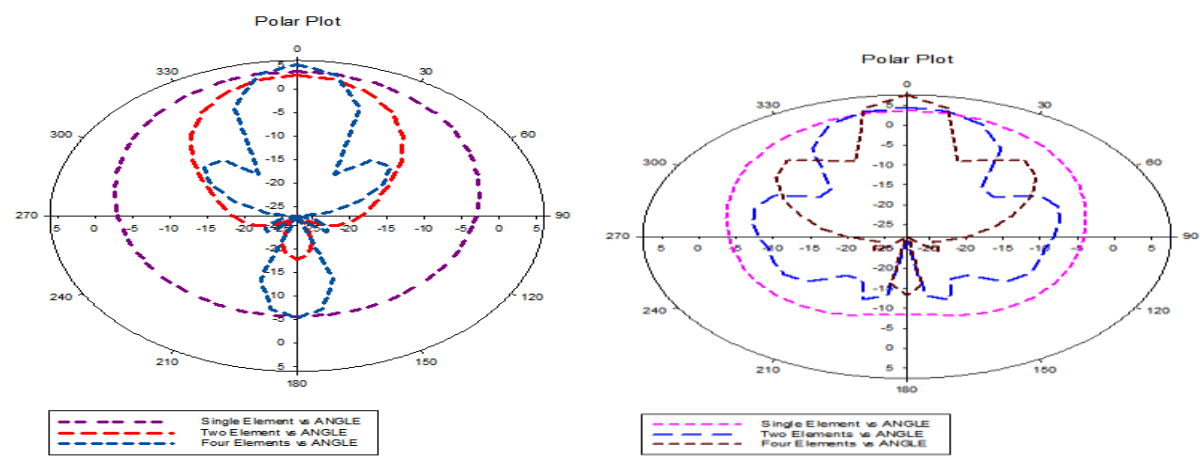

Figure 6 Simulated polar plot of the single element, $2 \times 1$ and 4 x 1 at $2.6 \mathrm{GHz}$ 


\subsubsection{Gain and Directivity}

Table 5 summarised the gain and directivity of the dual band microstrip patch array antenna. The directivity achieved for the array antennas at $1.8 \mathrm{GHz}$ and $2.6 \mathrm{GHz}$ are $5.96 \mathrm{~dB}$ and $6.46 \mathrm{~dB}, 9.16 \mathrm{~dB}$ and $8.91 \mathrm{~dB}, 11.2 \mathrm{~dB}$ and $12.9 \mathrm{~dB}$ for single, $2 \times 1$ elements and $4 \times 1$ elements array antennas respectively. Due to improvement in directivity of the array antenna, it can be ascertained that antenna gain and directivity increase as the number of the elements increased. Hence, a good directivity higher than $10 \mathrm{~dB}$ have been achieved for $4 \mathrm{x} 1$ elements array configuration and the antenna can be a very good candidate for LTE applications in Malaysia.

Table 5 Summarized results of the single element, $2 \times 1$ and 4 x 1 elements array antennas

\begin{tabular}{|c|c|c|c|c|c|}
\hline $\begin{array}{l}\text { Eleme } \\
\text { nts }\end{array}$ & $\begin{array}{c}\text { Resonant } \\
\text { Frequency } \\
\qquad(\mathrm{GHz})\end{array}$ & $\begin{array}{l}\text { Return } \\
\text { Loss S11 } \\
\\
\text { (dB) }\end{array}$ & $\begin{array}{l}\text { Magnitude of } \\
\text { Reflection } \\
\text { Coefficient } \\
|\mathrm{S} 11| \\
(\mathrm{MHz})\end{array}$ & $\begin{array}{l}\text { Gain } \\
\text { (dB) }\end{array}$ & Directivity \\
\hline \multirow{2}{*}{$\begin{array}{c}1- \\
\text { Element }\end{array}$} & 1.8 & -16.53 & 55 & 3.71 & 5.96 \\
\hline & 2.6 & -27.19 & 59 & 3.72 & 6.46 \\
\hline \multirow{2}{*}{$\begin{array}{c}2- \\
\text { Elements }\end{array}$} & 1.8 & -16.14 & 32 & 4.49 & 9.16 \\
\hline & 2.68 & -31.11 & 59 & 5.14 & 8.91 \\
\hline \multirow{2}{*}{$\begin{array}{c}4- \\
\text { Elements }\end{array}$} & 1.8 & -23.47 & 38 & 7.32 & 11.2 \\
\hline & 2.6 & -24.37 & 51 & 7.77 & 12.9 \\
\hline
\end{tabular}

It can be clearly observed that, the antenna gain and directivity for all configurations are always higher at $2.6 \mathrm{GHz}$ compared to $1.8 \mathrm{GHz}$. This may be due to the effect of the slot dimensions that affect the current distribution on the the patch antenna. 


\section{Conclusion}

Dual band microstrip patch array antenna was designed and implemented. The antenna was fabricated on FR4 substrate of thickness of $1.6 \mathrm{~mm}$ and dielectric constant of 4.6. The resonant frequencies of the single element, $2 \times 1$ elements and $4 \times 1$ elements antennas are $1.8 \mathrm{GHz}$ and $2.6 \mathrm{GHz}$ respectively. The maximum directivity achieved have been recorded as $5.96 \mathrm{~dB}$ and $6.46 \mathrm{~dB}$ (single), $9.16 \mathrm{~dB}$ and $8.91 \mathrm{~dB}(2 \times 1$ elements) and $11.2 \mathrm{~dB}$ and $12.9 \mathrm{~dB}(4$ $\mathrm{x} 1$ elements) at both frequencies. Meanwhile, the $-10 \mathrm{~dB}$ impedance bandwidth are obtained as $55 \mathrm{MHz}$ and $99 \mathrm{MHz}$ at $1.8 \mathrm{GHz}$ and $2.6 \mathrm{GHz}$ for the single element, $32 \mathrm{MHz}$ and $59 \mathrm{MHz}$ for $2 \times 1$ elements and $38 \mathrm{MHz}$ and $51 \mathrm{MHz}$ for $4 \times 1$ elements. The simulated and mesured results for single element and two elements are compared, and good agreement between the simulated and measured results was achieved. Hence, the antenna can be a good candidate for LTE applications. However in future work, other shapes can be employed to achieve higher gain and directivity. At the same time more antenna elements can be added so that higher gain can be obtained. There is also a need for the improvement of the bandwidth of the antenna. Many techniques could be employed to improve the antenna bandwidth such as using stacked patches, slot coupling and parasitic patches on the same plane. For future mobile communications, higher frequency of operation should be used to design the future dual band microstrip antenna, as the size of the antenna depends solely on the frequency of the antenna. The bigger the frequency of the dual band microstrip antenna, the smaller the size of the antenna. 


\section{References}

[1] M. Aziz, M. Shukor, M. Suaidi, and A. Salleh, "Design a 3.5 Antenna for Dual Band Application," International Journal of Emerging Technology and Advanced Engineering, vol. 2, pp. 486-492, 2012.

[2] H. Errifi, A. Baghdad, A. Badri, and A. Sahel, "Design and Analysis of Directive Microstrip Patch Array Antennas with Series, Corporate and Series-Corporate Feed Network," International Journal of Electronics and Electrical Engineering, article, 2015.

[3] S. J. LAKSHMI, K. Habibulla, and B. T. P. MADHAV, "Design and analysis of high gain array antenna for wireless communication applications," Leonardo Electronic Journal of Practices and Technologies, pp. 89-102, 2015.

[4] G. Karunakar, S. Sairam, and D. Reshma, "Analysis Of Linear And Planarantenna Arrays," IJSEAT, vol. 3, pp. 151-155, 2015.

[5] F. Adachi, "Keynote talk\# 1: Wireless evolution and challenges for 5G wireless networks," in Information and Computer Science (NICS), 2015 2nd National Foundation for Science and Technology Development Conference on, 2015, pp. xxi-xxii.

[6] C. A. Balanis, Antenna theory: analysis and design: John Wiley \& Sons, 2016.

[7] T. Mshvidobadze, "Evolution mobile wireless communication and LTE networks," in Application of Information and Communication Technologies (AICT), 2012 6th International Conference on, 2012, pp. 1-7.

[8] R. S. Khan and M. Ishfaq, "A Compact Microstrip Patch Antenna for LTE Applications," 2013.

[9] S. J. Navaratnam, "Malaysian spectrum licensing framework," Malaysian Communications and Multimedia Commission, 2014.

[10] H. Elesawy, W. Swelam, A. Fouda, I. M. Hafez, and P. No, "Design of Microstrip Array Antenna for Wireless Communication Application."

[11] L. C. Paul and N. Sultan, "Design, simulation and performance analysis of a line feed rectangular micro-strip patch antenna," International Journal of Engineering Sciences \& Emerging Technologies (IJESET), vol. 4, pp. 117-126, 2013.

[12] R. Garg, Microstrip antenna design handbook: Artech house, 2001.

[13] D. M. Pozar, Microwave and RF design of wireless systems: John Wiley \& Sons, Inc., 2000.

[14] Y. Huang and K. Boyle, Antennas: from theory to practice: John Wiley \& Sons, 2008.

[15] S. Maci, "Dual-frequency patch antennas Antennas and Propagation Magazine," in IEEE Dec, 1997.

[16] M. Zou and J. Pan, "Wide Dual-Band Circularly Polarized Stacked Rectangular Dielectric Resonator Antenna."

[17] T. N. Chang, "A dual-band antenna with coplanar ring and patch," in Antenna Technology: Small and Smart Antennas Metamaterials and Applications, 2007. IWAT'07. International Workshop on, 2007, pp. 243-246.

[18] H. binti Ibrahim and S. K. A. Rahim, "Dual Band Compact Size Microstrip Antenna Operating at $2.45 \mathrm{GHz}$ and $5.8 \mathrm{GHz}$ for WLAN Applications," Life Science Journal, vol. 11, 2014.

[19] W. Swelam, M. A. Soliman, A. Gomaa, and T. Taha, "Compact dual-band microstrip patch array antenna for MIMO 4G communication systems," in Antennas and Propagation Society International Symposium (APSURSI), 2010 IEEE, 2010, pp. 1-4.

[20] G. J. Moernaut and D. Orban, "The basics of antenna arrays," Orban Microwave Products, 2006.

[21] D. D. Harty, "Novel design of wide band rib-cage dipole array and its feeding networks," Worcester Polytechnic Institute, 2010.

[22] S. Yahya, "Design of 4 elements rectangular microstrip patch antenna with high gain for 2.4 GHz applications," Modern applied science, vol. 6, p. 68, 2011.

[23] C. K. C. a. A. K. B. A. De. , "Design and performance analysis of mocrostrip patch array antennas with different configurations "International Journal of Future Generation Communication and Networking, vol. 9, pp. 97-110, 2016. 